\title{
A Role for Pathogenesis-Related Proteins in Poly-Sensitized Allergic Patients with Eosinophilic Esophagitis: Clinical and Endoscopic Features
}

Erminia Ridolo ${ }^{1 *}$, Marcello Montagni ${ }^{1}$, Valerie Melli ${ }^{1}$, Elisa Olivieri', Fabiola Fornaroli ${ }^{2}$, Gian Luigi De' Angelis ${ }^{1}$, Cristoforo Incorvaia ${ }^{3}$ and Giorgio Walter Canonica ${ }^{4}$

${ }^{1}$ Department of Clinical and Experimental Medicine, University of Parma, Parma, Italy

${ }^{2}$ Gastroenterology and Operative Endoscopy Unit, University of Parma, Parma, Italy

${ }^{3}$ Pulmonary Rehabilitation Unit, ICP Hospital, Milan, Italy

${ }^{4}$ Allergy and Respiratory Diseases Clinic, DIMI, University of Genoa, IRCCS AOU San Martino-IST, Genoa, Italy

\begin{abstract}
Objective: Eosinophilic Esophagitis (EoE) is a chronic inflammatory disease of the esophagus often associated with atopy. Most EoE patients are poly-sensitized to inhalant and food allergens. Sensitization to pan-allergens is also frequent but their role in EoE is unclear. The aim of the study was to investigate the role of sensitization toward pathogenesis-related proteins $(\mathrm{PR})$ in patients with $\mathrm{EoE}$, and its relationship with clinical and endoscopic features.

Methods: A group of poly-sensitized patients was retrospectively analyzed, and clinical, endoscopic, and histological differences were compared between patients' sensitized and non-sensitized to PR-10 proteins.

Results: Dysphagia was more frequent in patients sensitized to PR-10 compared with non-sensitized subjects ( $83 \%$ vs. $42 \%, p=0.032$ ) while other presenting symptoms did not significantly differ between the two groups. The mean esophageal eosinophil peak was significantly higher in PR-10-sensitized patients $(p=0.047)$. As far as endoscopic findings were concerned, no difference was found between the two groups.
\end{abstract}

Conclusion: Sensitization to plant-food allergens such as PR-10 proteins seems relevant in poly-sensitized patients suffering from EoE and needs to be evaluated in order to test the result of an appropriate elimination diet.

Keywords: Eosinophilic esophagitis; Eosinophils; Birch pollen; PR10; Dysphagia; Esophagus; Dysphagia; Diet; Molecular allergy diagnostics; Food allergy

\section{Introduction}

Eosinophilic esophagitis (EoE) is a chronic inflammatory disease characterized by the presence of dysfunction symptoms and eosinophilic inflammation in the esophagus, without the involvement of other regions of the gastro-intestinal tract [1]. EoE is frequently associated with atopy (that is found in $50-80 \%$ of patients), although the causal relationship is not completely clear [2]. However, a pathogenic role of atopy was apparent in both epidemiological and experimental studies, with important diagnostic and therapeutic implications [3]. Most EoE patients, when tested by skin Skin Prick Test (SPT) and/or in vitro specific IgE assays show multiple positive results to foods and inhalant allergens, that defines the condition of poly-sensitization [4]. The presence of an IgE-mediated hypersensitivity to food antigens occurs in $15-43 \%$ of patients [5], while a history of allergic rhinitis is found in $40-75 \%$ of cases. Associations with asthma and atopic dermatitis occur in $14-70 \%$ and $4-60 \%$ of patients, respectively $[5,6]$. Despite these findings, the value of allergy testing to address dietary therapy is still under discussion [7-9]. Recently, molecular-based diagnostic methods have been introduced as a tool to define patient's sensitizations using recombinant allergenic proteins that can distinguish genuine, i.e. really sensitizing, allergens, from simply cross-reactive allergens in polysensitized patients [10]. Some authors reported that most EoE patients are sensitized to aeroallergens that cross-react with food allergens. In particular, sensitization to profilins and pathogenesis-related protein 10 (PR-10) is very common $[11,12]$, but their significance is very different. In fact, profilins are ubiquitary allergens with an insignificant clinical role, while for PR-10 the relationship with symptoms is acknowledged. PR-10 belongs to a family of proteins with a high degree of structural homology, which are present in pollens, fruits, and vegetables [13]. These molecules, once digested by pepsin, are degraded in the stomach, but are intact when passing through the esophagus, where they can be recognized by the immune system. Van Rhijn et al. reported that sensitization to birch pollen ( $\mathrm{rBet} \mathrm{v} 1$ ) with cross reactivity to foods via PR-10 protein occurs in $39 \%$ of adult EoE patients [12]. On the basis of this feature and the fact that PR-10 proteins occur naturally in many common plant foods, they may play an important role in EoE. For these reasons, we investigated the difference in presentation of symptoms, and endoscopic and histologic findings as well, in a group of poly-sensitized patients suffering from EoE sensitized to PR-10 proteins, compared to non-sensitized subjects.

\section{Methods}

We retrospectively analyzed 31 poly-sensitized patients ( 21 males, 10 females; mean age $21.3 \pm 11.4$ years) suffering from EoE. The disease was diagnosed according to international recommendations in the presence of typical symptoms and/or endoscopic findings associated with persistent esophageal eosinophilia ( $>15$ eosinophils/ high power field, HPF) despite full-dose proton pump inhibitor therapy [14]. In particular, dysphagia was defined by the indications of the World Gastroenterology Organisation Practice Guidelines [15].

*Corresponding author: Erminia Ridolo, Department of Clinical and Experimenta Medicine, University of Parma, via Gramsci 14. Parma 43126, Italy, Tel: 390521702028; Fax: 390521703920; E-mail: erminia.ridolo@unipr.it

Received September 16, 2014; Accepted November 28, 2014; Published December 05, 2014

Citation: Ridolo E, Montagni M, Melli V, Olivieri E, Fornaroli F, et al. (2014) A Role for Pathogenesis-Related Proteins in Poly-Sensitized Allergic Patients with Eosinophilic Esophagitis: Clinical and Endoscopic Features. J Allergy Ther 5: 199. doi:10.4172/2155-6121.1000199

Copyright: @ 2014 Ridolo E, et al. This is an open-access article distributed under the terms of the Creative Commons Attribution License, which permits unrestricted use, distribution, and reproduction in any medium, provided the original author and source are credited. 
Citation: Ridolo E, Montagni M, Melli V, Olivieri E, Fornaroli F, et al. (2014) A Role for Pathogenesis-Related Proteins in Poly-Sensitized Allergic Patients with Eosinophilic Esophagitis: Clinical and Endoscopic Features. J Allergy Ther 5: 199. doi:10.4172/2155-6121.1000199

Page 2 of 4

The reliability of the various symptoms of esophageal dysphagia was validated by the Mayo dysphagia questionnaire, that demostrated a good reproducibility, as assessed by kappa value, for heartburn, acid regurgitation, and food impaction, but not for odynophagia [16]. All biopsies were performed from four different sites of the esophagus by a single pathologist, who also reviewed the slides, considering for the analysis the highest eosinophils number. Endoscopies were performed by specialists from the Gastroenterology and digestive endoscopy Unit of the University Hospital of Parma. A positive history of allergic diseases was recorded with regard to rhinoconjunctivitis, asthma, atopic dermatitis, and food-related allergic symptoms prior to the diagnosis of EoE. Patients underwent SPT with standardized commercially available allergenic extracts (Alk Abellò, Madrid, Spain) for common aeroallergens and food allergens. Inhalant extracts included tree, grass, weed, and ragweed pollens; cat and dog epithelia, Dermatophagoides farinae, Dermatophagoides pteronyssinus, and mold spores (Alternaria, Cladosporium). Food allergens include egg, cow's milk, soybean, peanut, walnut, wheat, shrimp, fish, tomato, rice, peach, apple, and others based on clinical history. Histamine $(10 \mathrm{mg} /$ $\mathrm{ml}$ ) and normal saline were used as positive and negative controls, respectively. Subsequently, according to the results, molecular-based diagnostic methods were used to distinguish primary and crossreactive food allergen sensitizations by testing for serum-specific IgE antibodies with ImmunoCAP or, in some cases, ImmunoCAPISAC (Thermo Fischer Scientific, Sweden). The peripheral blood eosinophil count was also determined. The results were analyzed in order to investigate the difference in presentation of symptoms, and in endoscopic and histologic findings, in EoE patients sensitized to PR-10 proteins compared to non-sensitized subjects.

\section{Statistical analysis}

Statistical analysis was performed using the SAS computer program. Comparison of the variables was performed with the Chi square test, or Fisher's exact test (if cells with small values). The T-test was used for continuous variables. We used a regression analysis for testing the difference between the two groups, after adjusting for age and sex. $P$ values less than 0.05 were regarded as statistically significant.

\section{Results}

The mean duration of symptoms prior to inclusion of patients in the study was 10.2 months. All patients underwent treatment with proton pump inhibitors for at least two months before inclusion, but no patient had received previous specific treatment for EoE. All patients were poly-sensitized to inhalant or food allergens and $80.1 \%$ had a previous history of allergic diseases (Table 1). Most common symptoms were dysphagia (58\%), food impaction (48\%), and heartburn (39\%), dyspepsia (25\%), and nausea and vomiting (13\%); $71 \%$ of patients showed more than one symptom. Endoscopic findings included mucosal fragility and erosion, white plaques or exudates, rings or trachealization, and linear furrows as well as normal appearance. The average count of esophageal eosinophils per HPF was $25.9 \pm 11.2$. All biopsies were negative for eosinophilic infiltration. The majority (29 individuals, $93.5 \%$ ) of patients was sensitized to aeroallergens, and 24 patients (77.4\%) showed positive results for at least one food allergen. Twelve patients (39\%) were sensitized to birch pollen (rBet v1) and showed food cross-reactivity to PR-10 proteins from apple $(5 / 12)$, peach $(3 / 12)$, peanut $(6 / 12)$, kiwi $(2 / 12)$, soybean $(5 / 12)$, celery $(2 / 12)$, and hazelnut (2/12). Fifteen patients (48\%) were sensitized to profilins and three to lipid transfer proteins (LTP). Primary food allergen sensitization was found in 11 patients (35\%). Dysphagia was more

\begin{tabular}{|l|c|c|c|}
\hline & $\begin{array}{c}\text { PR-10 positive } \\
\text { (N=12) }\end{array}$ & $\begin{array}{c}\text { PR-10 negative } \\
\text { (N=19) }\end{array}$ & P value \\
\hline Age (years \pm SD) & $23.6 \pm 10.1$ & $19.9 \pm 12.2$ & 0.389 \\
\hline Male & 11 & 10 & 0.097 \\
\hline Female & 1 & 9 & 0.018 \\
\hline Atopic diseases & $12(100 \%)$ & $13(68.4 \%)$ & 0.056 \\
\hline Allergic Rhinitis & $10(83.3 \%)$ & $6(31.6 \%)$ & 0.003 \\
\hline Asthma & $7(58.3 \%)$ & $5(26.3 \%)$ & 0.059 \\
\hline Atopic dermatitis & $5(41.7 \%)$ & $2(10.5 \%)$ & 0.081 \\
\hline Oral allergy syndrome & $5(41.7 \%)$ & $3(15.8 \%)$ & 0.091 \\
\hline Food allergy & $3(25.0 \%)$ & $3(15.8 \%)$ & 0.338 \\
\hline Aeroallergens & $12(100 \%)$ & $17(89.4 \%)$ & 0.143 \\
\hline Food allergens & $12(100 \%)$ & $12(63.2 \%)$ & 0.008 \\
\hline Primary food allergen sensitization & $4(33.3 \%)$ & $7(36.8 \%)$ & 1 \\
\hline Cross reactivity to food allergens & $12(100 \%)$ & $4(21.1 \%)$ & $<0.001$ \\
\hline
\end{tabular}

Table 1: Characteristic of EoE patients.

\begin{tabular}{|l|c|c|c|c|}
\hline Symptoms & $\begin{array}{c}\text { Total } \\
(\mathbf{N}=31)\end{array}$ & $\begin{array}{c}\text { PR-10 positive } \\
(\mathbf{N = 1 2 )}\end{array}$ & $\begin{array}{c}\text { PR-10 negative } \\
\mathbf{( N = 1 9 )}\end{array}$ & P value \\
\hline Dysphagia & $18(58 \%)$ & $10(83 \%)$ & $8(42 \%)$ & $\mathbf{0 . 0 3 2}$ \\
\hline Food impaction & $15(48 \%)$ & $8(67 \%)$ & $7(37 \%)$ & n.s. \\
\hline Heartburn & $12(39 \%)$ & $5(42 \%)$ & $7(37 \%)$ & n.s. \\
\hline Dyspepsia & $8(25 \%)$ & $5(42 \%)$ & $3(16 \%)$ & n.s. \\
\hline Nausea and vomiting & $4(13 \%)$ & $1(8 \%)$ & $3(16 \%)$ & n.s. \\
\hline More than one & $22(71 \%)$ & $11(92 \%)$ & $11(58 \%)$ & n.s. \\
\hline
\end{tabular}

Table 2: Presenting symptoms

\begin{tabular}{|l|c|c|c|}
\hline & $\begin{array}{c}\text { PR-10 positive } \\
\mathbf{( N = 1 2 )}\end{array}$ & $\begin{array}{c}\text { PR-10 negative } \\
\mathbf{( N = 1 9 )}\end{array}$ & P value \\
\hline $\begin{array}{l}\text { Peripheral eosinophilia } \\
\text { (mean eosinophils/mL) }\end{array}$ & $528 \pm 393$ & $408 \pm 262$ & n.s. \\
\hline $\begin{array}{l}\text { Esophageal eosinophilia } \\
\text { (mean eosinophils/HPF) }\end{array}$ & $30.9 \pm 14.2$ & $22.6 \pm 7.5$ & $\mathbf{0 . 0 4 7}$ \\
\hline
\end{tabular}

Table 3: Peripheral and esophageal eosinophilia.

\begin{tabular}{|l|c|c|c|c|}
\hline EGDS & $\begin{array}{c}\text { Total } \\
(\mathbf{N}=\mathbf{3 1})\end{array}$ & $\begin{array}{c}\mathbf{P R}-\mathbf{1 0} \text { positive } \\
\mathbf{( N = 1 2 )}\end{array}$ & $\begin{array}{c}\mathbf{P R - 1 0} \text { negative } \\
\mathbf{( N = 1 9 )}\end{array}$ & $\mathbf{P}$ value \\
\hline Normal & $5(16 \%)$ & $2(17 \%)$ & $3(16 \%)$ & n.s. \\
\hline Mucosal fragility/erosion & $18(58 \%)$ & $7(58 \%)$ & $11(58 \%)$ & n.s. \\
\hline White plaques or exudates & $6(19 \%)$ & $3(25 \%)$ & $3(16 \%)$ & n.s. \\
\hline Rings/trachealization & $5(16 \%)$ & $2(17 \%)$ & $3(16 \%)$ & n.s. \\
\hline Linear furrows & $4(13 \%)$ & $2(17 \%)$ & $2(10 \%)$ & n.s. \\
\hline
\end{tabular}

Table 4: Endoscopic features.

frequent in patients sensitized to PR-10 proteins compared with nonsensitized subjects ( $83 \%$ versus $42 \%, \mathrm{p}=0.032$ ) while other presenting symptoms such as food impaction, heartburn, dyspepsia, or nausea and vomiting did not significantly differ between the two groups (Table 2). There was no significant difference between adult and pediatric patients in clinical features. Moreover, the mean esophageal eosinophils peak was significantly higher in PR-10-sensitized patients (Table 3). These differences remained statistically significant after adjusting for age and sex. As far as endoscopic findings were concerned, no difference was found between the two groups (Table 4).

\section{Discussion}

The role of atopy in EoE is still debated $[1,2]$, because positive results to allergy testing do not necessarily indicate the clinical responsibility of the identified allergens, that may be simply related to asymptomatic sensitization [4]. Also, in a recent study on $30 \mathrm{EoE}$ patients the treatment with the anti-IgE Omalizumab was not effective 
Citation: Ridolo E, Montagni M, Melli V, Olivieri E, Fornaroli F, et al. (2014) A Role for Pathogenesis-Related Proteins in Poly-Sensitized Allergic Patients with Eosinophilic Esophagitis: Clinical and Endoscopic Features. J Allergy Ther 5: 199. doi:10.4172/2155-6121.1000199

Page 3 of 4

on symptoms or eosinophil counts in biopsy samples compared with placebo [17]. The patients with EoE we studied had a clinical presentation including the symptoms, such as heartburn, food impaction, and dyspepsia, that were validated by the Mayo dysphagia questionnaire [14]. Both inhalant and food allergens seem to play a role in the pathophysiology of EoE [18], as demonstrated for aeroallergens in experimental animal models, while in humans it was suggested by the fact that eosinophil infiltration may be observed in esophageal tissue of patients with respiratory allergy during the symptomatic period $[19,20]$. The important role of food allergens in EoE was shown by an improvement of symptoms and resolution of histological abnormalities after specific elimination diets [21-23]. Thus, in EoE, the role of a cross-reactive plant food allergen such as PR-10 proteins seems to be of great interest in promoting eosinophilic inflammation in the esophagus of sensitized patients, not only as an "aeroallergen trigger" but also by activating a Th2 response of the immune system after contact with the esophageal mucosa. PR-10 proteins, due to their important biologic role in stress signaling [24], are largely present in vegetables and act in humans as major allergens [13]. In our patients, who were all allergic and poly-sensitized to inhalant and food allergens, the sensitization toward PR-10 proteins was associated with EoE. Of interest, the occurrence of validated symptoms such as heartburn and food impaction was more frequent (though not reaching statistical significance) in patients sensitized to PR-10 (Table 2). In particular, the presence of PR-10 sensitization was significantly associated with the presence of dysphagia at the onset of the disease, and with a more severe esophageal eosinophilia. It seems reasonable to assume that the persistent contact with the allergen induces in the esophagus an allergic inflammation similar to that occurring for example in the nasal mucosa of patients allergic to birch pollen, the major allergen of which is a PR-10, but this should be investigated by specific studies. Dietary treatment has been demonstrated to be effective in patients with EoE and concomitant food allergy, but while the clinical and histological response is high with an elemental diet or six foods elimination diet (SFED) [21-23], the efficacy of a selective elimination diet based on skin testing is satisfactory in children but low in adult patients $[8,25]$. According to our results, a possible sensitization to PR-10 proteins is worthy of verification with molecular-based allergy diagnostics in order to test the result of an appropriate elimination diet excluding all the foods containing PR-10. Molecular-based allergy diagnostics has the unique ability to allow for risk assessment in patients with food allergies [10]. It is known that foods contain allergenic molecules that can be either stable or labile to heat and digestion. While labile allergens are associated with local reactions (typically oral symptoms), and the cooked food containing such allergens is often tolerated, stable allergens can cause severe systemic reactions. Thus, the management of patients can be improved by precise knowledge of a sensitization profile, allowing the implementation of a proper elimination diet. The immune mechanisms to explain why not all EoE patients sensitized to PR-10 show other IgE-mediated symptoms, such as oral allergy syndrome, remain unclear. A previous study demonstrated that patients with eosinophilic gastrointestinal disease have a predominance of IL-5-positive Th2 cells to peanut antigens, as compared with patients with peanut anaphylaxis who have predominantly IL-5-negative Th2 cells [26]. The role of avoidance of culprit foods in the management of food allergy is well defined [27], but further studies are necessary to define the mechanisms that underlie distinct immunologic reactions to foods. On the basis of current evidence, clinical differences between anaphylactic food allergy and eosinophil-associated gastrointestinal disorders seem to be related to different Th2 responses to foods. In particular, studies addressing the clinical and immunological effects of a diet free from PR-10-containing foods will allow the role of this important group of allergens in EoE to be verified.

\section{References}

1. Dellon ES (2013) Eosinophilic esophagitis. Gastroenterol Clin North Am 42 133-153.

2. Park H (2014) An Overview of Eosinophilic Esophagitis. Gut Liver 8: 590-597.

3. Ridolo E, Montagni M, Olivieri E, Rogkakou A, De' Angelis GL, et al. (2012) Eosinophilic esophagitis: which role for food and inhalant allergens? Asia Pac Allergy 2: 237-241.

4. Migueres M, Dávila I, Frati F, Azpeitia A, Jeanpetit Y, et al. (2014) Types of sensitization to aeroallergens: definitions, prevalences and impact on the diagnosis and treatment of allergic respiratory disease. Clin Transl Allergy 4 16.

5. Roy-Ghanta S, Larosa DF, Katzka DA (2008) Atopic characteristics of adult patients with eosinophilic esophagitis. Clin Gastroenterol Hepatol 6: 531-535.

6. Erwin EA, James HR, Gutekunst HM, Russo JM, Kelleher KJ, et al. (2010) Serum IgE measurement and detection of food allergy in pediatric patients with eosinophilic esophagitis. Ann Allergy Asthma Immunol 104: 496-502.

7. Straumann A (2013) Eosinophilic esophagitis: a bulk of mysteries. Dig Dis 31: 6-9.

8. Molina-Infante J, Martin-Noguerol E, Alvarado-Arenas M, Porcel-Carreño SL, Jimenez-Timon S, et al. (2012) Selective elimination diet based on skin testing has suboptimal efficacy for adult eosinophilic esophagitis. J Allergy Clin Immunol 130: 1200-1202.

9. Reddy V, Ghaffari G (2013) Eosinophilic esophagitis: review of nonsurgical treatment modalities. Allergy Asthma Proc 34: 421-426.

10. Canonica GW, Ansotegui IJ, Pawankar R, Schmid-Grendelmeier P, van Hage $\mathrm{M}$, et al. (2013) A WAO - ARIA - GA²LEN consensus document on molecularbased allergy diagnostics. World Allergy Organ J 6: 17.

11. Simon D, Straumann A, Dahinden C, Simon HU (2013) Frequent sensitization to Candida albicans and profilins in adult eosinophilic esophagitis. Allergy 68: 945-948.

12. van Rhijn BD, van Ree $R$, Versteeg $S A$, Vlieg-Boerstra BJ, Sprikkelman AB, et al. (2013) Birch pollen sensitization with cross-reactivity to food allergens predominates in adults with eosinophilic esophagitis. Allergy 68: 1475-1481.

13. Breiteneder $\mathrm{H}$, Ebner C (2000) Molecular and biochemical classification of plant-derived food allergens. J Allergy Clin Immunol 106: 27-36.

14. Liacouras CA, Furuta GT, Hirano I, Atkins D, Attwood SE, et al. (2011) Eosinophilic esophagitis: updated consensus recommendations for children and adults. J Allergy Clin Immunol 128: 3-20.

15. www.worldgastroenterology.org/assets/downloads/en/pdf/guidelines/08

16. Grudell AB, Alexander JA, Enders FB, Pacifico R, Fredericksen M, et al. (2007) Validation of the Mayo Dysphagia Questionnaire. Dis Esophagus 20: 202-205.

17. Clayton F, Fang JC, Gleich GJ, Lucendo AJ, Olalla JM, et al. (2014) Eosinophilic esophagitis in adults is associated with IgG4 and not mediated by IgE. Gastroenterology 147: 602-609.

18. Blatman KH, Ditto AM (2012) Chapter 26: Eosinophilic esophagitis. Allergy Asthma Proc 33 Suppl 1: S88-90.

19. Mishra A, Hogan SP, Brandt EB, Rothenberg ME (2001) An etiological role for aeroallergens and eosinophils in experimental esophagitis. J Clin Invest 107: 83-90.

20. Onbasi K, Sin AZ, Doganavsargil B, Onder GF, Bor S, et al. (2005) Eosinophil infiltration of the oesophageal mucosa in patients with pollen allergy during the season. Clin Exp Allergy 35: 1423-1431.

21. Markowitz JE, Spergel JM, Ruchelli E, Liacouras CA (2003) Elemental diet is an effective treatment for eosinophilic esophagitis in children and adolescents. Am J Gastroenterol 98: 777-782.

22. Kagalwalla AF, Sentongo TA, Ritz S, Hess T, Nelson SP, et al. (2006) Effect of six-food elimination diet on clinical and histologic outcomes in eosinophilic esophagitis. Clin Gastroenterol Hepatol 4: 1097-1102.

23. Lucendo AJ, Arias Á, González-Cervera J, Yagüe-Compadre JL, Guagnozzi D 
Citation: Ridolo E, Montagni M, Melli V, Olivieri E, Fornaroli F, et al. (2014) A Role for Pathogenesis-Related Proteins in Poly-Sensitized Allergic Patients with Eosinophilic Esophagitis: Clinical and Endoscopic Features. J Allergy Ther 5: 199. doi:10.4172/2155-6121.1000199

Page 4 of 4

et al. (2013) Empiric 6-food elimination diet induced and maintained prolonged remission in patients with adult eosinophilic esophagitis: a prospective study on the food cause of the disease. J Allergy Clin Immunol 131: 797-804.

24. Agarwal P, Agarwal PK (2014) Pathogenesis related-10 proteins are small, structurally similar but with diverse role in stress signaling. Mol Biol Rep 41 : 599-611.
25. Spergel JM, Beausoleil JL, Mascarenhas M, Liacouras CA (2002) The use of skin prick tests and patch tests to identify causative foods in eosinophilic esophagitis. J Allergy Clin Immunol 109: 363-368.

26. Prussin C, Lee J, Foster B (2009) Eosinophilic gastrointestinal disease and peanut allergy are alternatively associated with IL-5+ and IL-5(-) T(H)2 responses. J Allergy Clin Immunol 124: 1326-1332.

27. Fogg MI, Spergel JM (2003) Management of food allergies. Expert Opin Pharmacother 4: 1025-1037. 